\title{
O potássio atenua os efeitos do déficit hídrico em mudas de pereiro (Aspidosperma pyrifolium Mart. \& Zucc.)
}

\section{Potassium mitigates the water deficit effects in Aspidosperma pyrifolium Mart. \& Zucc. seedlings}

George Martins de França ${ }^{1 *}$, Antonio Lucineudo de Oliveira Freire ${ }^{1}$, Antônio Wesly Batista ${ }^{1}$ Cheila Deisy Ferreira ${ }^{1}$, Débora Raquel dos Santos Ferreira ${ }^{1}$

\begin{abstract}
RESUMO
Este estudo teve como objetivo verificar os efeitos da baixa disponibilidade de água às plantas jovens de pereiro e o papel da adubação potássica na atenuação desses efeitos. Os tratamentos foram dispostos em delineamento inteiramente casualizado (DIC), distribuídos em esquema fatorial 3 x 3 sendo três níveis de água [100\%cp (capacidade de pote) (controle), $50 \% \mathrm{cp}$ (déficit moderado) e $25 \% \mathrm{cp}$ (déficit severo)] e quatro doses de potássio $\left(0,50,100\right.$ e $\left.150 \mathrm{mg} \mathrm{dm}{ }^{3} \mathrm{~K}\right)$, com quatro repetições. Foram avaliadas a condutância estomática $(G s)$, taxa de transpiração $(E)$, fotossíntese $(A)$, eficiência intrínseca no uso da água $(A / G s) \mathrm{e}$ eficiência de carboxilação $(\mathrm{A} / \mathrm{C} i)$. Os parâmetros avaliados foram afetados negativamente pelo déficit hídrico, mas influenciados positivamente pelo potássio, com aumentos nos valores à medida que se aumentou a quantidade de $\mathrm{KCl}$. As plantas mantidas em solo com umidade de $50 \% \mathrm{cp}$, apresentaram os melhores resultados, constituindo-se em uma possibilidade de economia de água durante a fase de produção das mudas de pereiro. Recomenda-se a adubação com $100 \mathrm{mg} \mathrm{dm}^{3} \mathrm{~K}$ e manutenção do substrato com $50 \% \mathrm{cp}$ de umidade, por proporcionar maiores condutância estomática, taxa fotossintética e eficiência de carboxilação.
\end{abstract}

Palavras-chave: Adubação potássica; Estresse hídrico; Trocas gasosas.

\begin{abstract}
This study aimed to verify the effects of low water availability on young pear trees and the role of potassium fertilization in attenuating these effects. The treatments were arranged in a completely randomized design (DIC), distributed in a 3x3 factorial scheme, with three water levels [100\%pc (pot capacity) (control), $50 \%$ pc (moderate deficit) and 25\%pc (severe deficit)] and four doses of potassium $(0,50,100$ and $150 \mathrm{mg}$ $\left.\mathrm{dm}^{3} \mathrm{~K}\right)$, with four replications. The stomatal conductance $(G s)$, transpiration rate $(E)$, photosynthesis $(A)$, intrinsic water use efficiency $(A / g s)$ and carboxylation efficiency $(A / C i)$ were evaluated. The parameters evaluated were negatively affected by water deficit, but positively influenced by potassium, with increases as the amount of $\mathrm{KCl}$ enhanced. The plants kept in soil with humidity of 50\% cp, presented the best results, constituting a possibility of saving water during the "pereiro" seedlings production. Fertilization with 100 $\mathrm{mg} \mathrm{dm} \mathrm{m}^{3} \mathrm{~K}$ and maintenance of the substrate with $50 \% \mathrm{pc}$ of moisture is recommended, as it provides greater stomatal conductance, photosynthetic rate and carboxylation efficiency.
\end{abstract}

Keywords: potassium fertilization; Water déficit; Gas exchange

${ }^{1}$ Universidade Federal de Campina Grande - UFCG.

*E-mail: george.martins.aurora9@gmail.com 


\section{INTRODUÇÃO}

A água é um dos fatores abióticos mais importantes para as plantas; porém elas são submetidas a períodos de déficit hídrico do solo durante seu ciclo de vida. A previsões e os diferentes cenários disponíveis para mudanças climáticas sugerem um aumento da aridez para as regiões semiáridas do globo (CHAVES, FLEXAS e PINHEIRO, 2009; IPCC, 2014). Esse fator, aliado ao aumento na população, levará a uma super exploração dos recursos hídricos para fins agrícolas e maiores restrições ao crescimento e à sobrevivência das plantas (CHAVES, MAROCO e PEREIRA, 2003; PASSIOURA, 2007).

O semiárido do Nordeste do Brasil apresenta como principais características temperaturas elevadas e precipitação pluviométrica distribuída irregularmente, com ampla variação anual, apresentando ciclos periódicos de seca. O tipo de vegetação predominante é a Caatinga, predominando árvores de baixo porte e arbustos, os quais perdem completamente as folhas durante o período seco.

A forma com que as plantas toleram a baixa disponibilidade de água no solo é fundamental para o seu crescimento e estabelecimento em regiões com problema de seca frequente. Porém, os mecanismos desenvolvidos visando tolerar essa condição adversa variam de acordo com a intensidade e duração do estresse, bem como com a espécie e o estádio de desenvolvimento do vegetal (CHAVES, MAROCO e PEREIRA, 2003).

A baixa disponibilidade de água no solo promove alterações morfológicas e fisiológicas nas plantas, interferindo em vários processos metabólicos essenciais à vida das mesmas (LARCHER, 2004, PINHEIRO; CHAVES, 2011). Com a diminuição na disponibilidade da água para as raízes, há redução no potencial hídrico celular e, consequentemente, na turgescência das mesmas. Posteriormente, ocorre o fechamento estomático, reduzindo a perda de água por transpiração (SCALON et al., 2011; VALADARES, PAULA e PAULA, 2014; FERNANDES-SILVA et al., 2016). No entanto, há decréscimo na assimilação fotossintética do carbono, reduzindo a atividade da Rubisco, resultando em baixa produção de assimilados, resultando em diminuição na área foliar e no crescimento das plantas (VANDOORNE et al., 2012; VALADARES, PAULA e PAULA, 2014; PADILHA et al., 2016). 
Porém, os efeitos do déficit hídrico não são apenas de natureza estomática, mas também em aspectos não-estomáticos (LIMA, JARVIS e RHIZOPOULOU, 2003; FLEXAS et al., 2004; BOUSSADIA et al., 2008; DIAS; BRÜGGERMANN, 2010).

O pereiro (Aspidorperma pyrifolim Mart. \& Zucc.), pertencente à família Apocynaceae, se constituindo em uma das mais representativas espécies da Caatinga, é uma árvore de tamanho médio (7-8 m de altura), de casca lisa e acinzentada, com cerne amarelo e um pouco elástico, prestando-se a trabalhos de marcenaria e carpintaria (BRAGA, 2015). É uma planta decídua, xerófita e heliófita, que se adapta a todos os tipos de textura e profundidade de solos, sendo capaz de crescer até em lugares muito erodidos (MAIA, 2004). Sua madeira pode ser usada para a produção de estacas, carvão e lenha, com elevado poder calorífico; a casca tem efeito tônico, sendo empregada como remédio para estômago; na veterinária popular, é usado no tratamento de ectoparasitoses dos animais domésticos (MAIA, 2004). Este autor relata ainda que a espécie pode ser empregada na arborização urbana e é indicada para a recuperação de solos degradados e na primeira fase de (re)florestamentos mistos.

Em virtude da carência de estudos com o pereiro na fase de mudas, principalmente em relação aos efeitos da deficiência hídrica, desenvolveu-se este estudo com o objetivo de verificar os efeitos da baixa disponibilidade de água em mudas de pereiro e o papel da adubação potássica na atenuação desses efeitos, na fase de viveiro.

\section{MATERIAL E MÉTODOS}

O experimento foi conduzido em ambiente protegido (telado), no Viveiro Florestal do Centro de Saúde e Tecnologia Rural da Universidade Federal de Campina Grande (CSTR/UFCG), Patos-PB, coordenadas geográficas 703’34” S e 37¹2”30" O.

O solo utilizado no experimento, coletado na Fazenda Nupeárido (CSTR/UFCG), foi destorroado, peneirado e submetido à análise física e de fertilidade, no Laboratório de Análise de Solo e Água da UFCG. O solo recebeu $50 \mathrm{mg}$ de N e $250 \mathrm{mg}$ de P para cada $\mathrm{dm}^{3}$ de substrato (FURTINI NETO et al., 1999), usando-se como fonte, respectivamente, sulfato de amônio, superfosfato simples e cloreto de potássio. Após a distribuição destes no solo, foi adicionado esterco bovino (2:1 v/v), misturando-se cuidadosamente, produzindo-se assim o substrato para o crescimento das plantas, o qual foi colocado em vasos confeccionados em garrafas tipo pet $(1,8 \mathrm{Kg}$ de substrato). 
Foram colocadas três sementes por vaso e, aos 45 dias após a emergência (DAE), foi feito o desbaste, deixando a plântula mais vigorosa, procurando-se manter a uniformidade entre os vasos. As plântulas foram irrigadas uma vez por dia, procurandose manter a umidade do substrato próximo a $100 \%$ da capacidade de retenção (capacidade de pote - cp), até o início dos tratamentos hídricos, o que ocorreu aos 60 dias após a emergência (DAE).

Os tratamentos foram distribuídos em esquema fatorial $3 \times 4$, dispostos em delineamento inteiramente casualizado (DIC), correspondendo a três tratamentos hídricos [100\% cv (controle-CT, 50\% cv (déficit hídrico moderado-DM) e 25\% cv (déficit hídrico severo-DS)] e três doses suplementares de potássio (0, 50, 100 e $150 \mathrm{mg} \mathrm{dm}{ }^{3}$ de K), com quatro repetições, totalizando 48 plantas. As doses correspondem, respectivamente, a zero, $0,5,1,0$ e 1,5 vezes a quantidade de $\mathrm{K}$ recomendada na adubação do substrato.

O potássio $(\mathrm{KCl})$ foi dissolvido em água e fornecido de forma parcela, sendo a metade da dose na semeadura e a outra metade no momento do desbaste, de acordo com o tratamento. A irrigação dos vasos foi durante a condução do experimento foi realizada manualmente, controlada através de pesagem, segundo o tratamento hídrico avaliado.

As variáveis foram avaliadas aos 150 após o início dos tratamentos (DAIT) (210 DAE). Utilizando-se o analisador portátil de fotossíntese (IRGA) LCpro-SD (ADC BioScientific Ltd.), foram avaliadas a taxa de transpiração $(E)$, condutância estomática $\left(G_{s}\right)$, taxa de fotossíntese $(A)$ e a concentração interna de $\mathrm{CO}_{2}(C i)$ em folhas completamente expandidas inseridas no terceiro nó a partir do ápice das plantas, entre 10:00 e 11:00 horas da manhã, com a radiação fotossinteticamente ativa (PAR) do equipamento ajustada para $1200 \mu \mathrm{mol} \mathrm{m} \mathrm{s}^{-2}$.

Através dos valores de $A$ e $g_{s}$ foi calculada a Eficiência intrínseca no uso da água (EUAi) e pela razão $A / C i$, a Eficiência de carboxilação.

Os dados foram submetidos à análise de variância e as médias comparadas pelo teste de Tukey, ao nível de 5\% de probabilidade, utilizando-se o software ASSISTAT versão 7.7 (SILVA; AZEVEDO, 2016).

\section{RESULTADOS E DISCUSSÃO}

Em relação à condutância estomática $(g s)$ (Tabela 1), verificou-se elevação à medida que a dose de $\mathrm{K}$ aumentava até $100 \mathrm{mg} \mathrm{dm}^{3} \mathrm{~K}$, diminuindo em seguida a $150 \mathrm{mg}$ $\mathrm{dm}^{3} \mathrm{~K}$, independentemente do nível de água empregado. Quando se compara os níveis de 
água, em cada dose de K, percebe-se ampla variação dos valores de $g s$, dependendo da dose utilizada; porém, as plantas que receberam 100 e $150 \mathrm{mg} \mathrm{dm}^{3}$ e sob déficit hídrico moderado, mantiveram maior condutância estomática.

Tabela 1 - Condutância estomática (gs) de plantas de pereiro em função dos teores de água do vaso e da adubação potássica.

\begin{tabular}{cllll}
\hline Níveis de água & \multicolumn{4}{c}{ Doses de $\mathbf{K}\left(\mathbf{m g ~ d m}^{-3}\right)$} \\
\cline { 2 - 5 }$(\boldsymbol{\%} \mathbf{c p})$ & $\mathbf{0}$ & $\mathbf{5 0}$ & $\mathbf{1 0 0}$ & $\mathbf{1 5 0}$ \\
\hline $100(\mathrm{CT})$ & $0,28 \mathrm{bA}$ & $0,31 \mathrm{aA}$ & $0,34 \mathrm{aB}$ & $0,26 \mathrm{bB}$ \\
$50(\mathrm{EM})$ & $0,22 \mathrm{cB}$ & $0,36 \mathrm{bA}$ & $0,45 \mathrm{aA}$ & $0,35 \mathrm{bA}$ \\
$25(\mathrm{ES})$ & $0,14 \mathrm{bC}$ & $0,32 \mathrm{aA}$ & $0,33 \mathrm{aB}$ & $0,18 \mathrm{bC}$ \\
\hline
\end{tabular}

Letras iguais, minúsculas nas linhas e maiúsculas nas colunas, não diferem estatisticamente entre si pelo teste de Tukey $(\mathrm{P} \leq 0,05)$. CT: controle; EM: déficit hídrico moderado; ES: déficit hídrico severo.

De acordo com a Tabela 2, verifica-se que as menores taxas de transpiração $(E)$ foram obtidas nas plantas que não receberam $\mathrm{K}$, ao passo que as plantas adubadas com $100 \mathrm{mg} \mathrm{dm}^{-3} \mathrm{~K}$ apresentaram maior valor de $E$. Em relação aos tratamentos hídricos, as plantas sob déficit hídrico severo e controle apresentaram menor e maior taxa de transpiração, respectivamente, independente da dose de $\mathrm{K}$ que receberam, exceto na dose de $100 \mathrm{mg} \mathrm{dm}^{-3} \mathrm{~K}$, que proporcionou a maior transpiração nas plantas sob déficit hídrico moderado, evidenciando o efeito positivo desta interação.

Tabela 2 - Taxa de transpiração $(E)$ de plantas de pereiro em função dos níveis de água e da adubação potássica.

\begin{tabular}{ccccc}
\hline Níveis de água & \multicolumn{4}{c}{ Doses de $\mathbf{K}\left(\mathbf{m g ~ d m}^{-3}\right)$} \\
\cline { 2 - 5 }$(\boldsymbol{\%} \mathbf{c p})$ & $\mathbf{0}$ & $\mathbf{5 0}$ & $\mathbf{1 0 0}$ & $\mathbf{1 5 0}$ \\
\hline $100(\mathrm{CT})$ & $5,23 \mathrm{bA}$ & $5,69 \mathrm{bA}$ & $6,59 \mathrm{aB}$ & $5,43 \mathrm{bA}$ \\
$50(\mathrm{DM})$ & $4,25 \mathrm{bB}$ & $4,16 \mathrm{bB}$ & $7,19 \mathrm{aA}$ & $4,49 \mathrm{bB}$ \\
$25(\mathrm{DS})$ & $3,08 \mathrm{bC}$ & $3,96 \mathrm{bB}$ & $5,03 \mathrm{aC}$ & $3,27 \mathrm{bC}$
\end{tabular}

Letras iguais, minúsculas nas linhas e maiúsculas nas colunas, não diferem estatisticamente entre si pelo teste de Tukey $(\mathrm{P} \leq 0,05)$. CT: controle; EM: déficit hídrico moderado; ES: déficit hídrico severo.

Independentemente da quantidade de $\mathrm{K}$ fornecida, a fotossíntese das plantas diminuiu à proporção que o estresse se intensificou (Tabela 3), sendo que nas plantas que 
receberam K, a manutenção das mesmas sob 50\%cp proporcionou os melhores valores. No entanto, o uso de $100 \mathrm{mg} \mathrm{dm^{3 }} \mathrm{K}$ possibilitou a obtenção das maiores taxas fotossintéticas, com os melhores resultados obtidos na interação $50 \%$ cp x100 mg dm${ }^{3} \mathrm{~K}$.

Tabela 3 - Taxa de fotossíntese $(A)$ de plantas de pereiro em função dos teores de água do vaso e da adubação potássica.

\begin{tabular}{ccccc}
\hline Níveis de água & \multicolumn{4}{c}{ Doses de $\mathbf{K}\left(\mathbf{m g ~ d m}^{-\mathbf{3}}\right)$} \\
\cline { 2 - 5 }$(\boldsymbol{\%} \mathbf{c p})$ & $\mathbf{0}$ & $\mathbf{5 0}$ & $\mathbf{1 0 0}$ & $\mathbf{1 5 0}$ \\
\hline $100(\mathrm{CT})$ & $13,54 \mathrm{cA}$ & $16,12 \mathrm{abA}$ & $17,03 \mathrm{aB}$ & $15,02 \mathrm{bB}$ \\
$50(\mathrm{EM})$ & $12,56 \mathrm{cA}$ & $19,34 \mathrm{bA}$ & $23,11 \mathrm{aA}$ & $19,89 \mathrm{bA}$ \\
$25(\mathrm{ES})$ & $5,78 \mathrm{cB}$ & $9,11 \mathrm{bB}$ & $14,02 \mathrm{aC}$ & $9,01 \mathrm{bC}$ \\
\hline
\end{tabular}

Letras iguais, minúsculas nas linhas e maiúsculas nas colunas, não diferem estatisticamente entre si pelo teste de Tukey $(\mathrm{P} \leq 0,05)$. CT: controle; EM: déficit hídrico moderado; ES: déficit hídrico severo.

Ocorreu elevação na EUAi das plantas com o aumento na dose de $\mathrm{K}$ fornecida (Tabela 4) e, semelhante ao observado nas variáveis gs (Tabela 1) e $A$ (Tabela 3), em cada dose de K utilizada, ocorreram decréscimos nos valores com a redução no nível de água imposto.

Tabela 4 - Eficiência intrínseca no uso da água $(E U A i)$ de plantas de pereiro em função dos teores de água do vaso e da adubação potássica.

\begin{tabular}{ccccc}
\hline Níveis de água & \multicolumn{4}{c}{ Doses de K $\left(\mathbf{m g ~ d ~ ^ { - 3 } )}\right.$} \\
\cline { 2 - 5 }$(\% \mathbf{c p})$ & $\mathbf{0}$ & $\mathbf{5 0}$ & $\mathbf{1 0 0}$ & $\mathbf{1 5 0}$ \\
\hline $100(\mathrm{CT})$ & $48,36 \mathrm{bB}$ & $52,01 \mathrm{bB}$ & $50,09 \mathrm{bA}$ & $57,77 \mathrm{aA}$ \\
$50(\mathrm{EM})$ & $57,09 \mathrm{bA}$ & $69,07 \mathrm{aA}$ & $51,35 \mathrm{cA}$ & $56,82 \mathrm{bA}$ \\
$25(\mathrm{ES})$ & $41,28 \mathrm{bC}$ & $28,44 \mathrm{cC}$ & $42,48 \mathrm{bB}$ & $50,05 \mathrm{aB}$
\end{tabular}

Letras iguais, minúsculas nas linhas e maiúsculas nas colunas, não diferem estatisticamente entre si pelo teste de Tukey $(\mathrm{P} \leq 0,05)$. CT: controle; EM: déficit hídrico moderado; ES: déficit hídrico severo.

Em relação à eficiência de carboxilação, verificou-se o mesmo comportamento das variáveis citadas anteriormente, com elevação nos valores com o acréscimo na dose de $\mathrm{K}$ fornecida, em todos os regimes hídricos, à proporção que o tempo do início dos tratamentos aumentou (Tabela 5). 
Além disso, as plantas mantidas a 50\%cp apresentaram o melhor desempenho (Tabelas 1 a 5), em todas as doses de $\mathrm{K}$ fornecidas, constituindo-se em uma vantagem em virtude da economia hídrica durante a fase de produção de mudas de pereiro.

Tabela 5 - Eficiência de carboxilação $(A / C i)$ de plantas de pereiro em função dos teores de água do vaso e da adubação potássica.

\begin{tabular}{ccccc}
\hline Níveis de & \multicolumn{4}{c}{ Doses de $\mathbf{~}\left(\mathbf{m g ~ d m}^{-3}\right)$} \\
água & $\mathbf{\%} \mathbf{c p})$ & $\mathbf{5 0}$ & $\mathbf{1 0 0}$ & $\mathbf{1 5 0}$ \\
\hline $100(\mathrm{CT})$ & $0,055 \mathrm{cA}$ & $0,068 \mathrm{aB}$ & $0,072 \mathrm{aB}$ & $0,063 \mathrm{bB}$ \\
$50(\mathrm{EM})$ & $0,054 \mathrm{cA}$ & $0,085 \mathrm{bA}$ & $0,110 \mathrm{aA}$ & $0,084 \mathrm{bA}$ \\
$25(\mathrm{ES})$ & $0,039 \mathrm{cB}$ & $0,047 \mathrm{bC}$ & $0,058 \mathrm{aC}$ & $0,046 \mathrm{bC}$
\end{tabular}

Letras iguais, minúsculas nas linhas e maiúsculas nas colunas, não diferem estatisticamente entre si pelo teste de Tukey $(\mathrm{P} \leq 0,05)$. CT: controle; EM: déficit hídrico moderado; ES: déficit hídrico severo.

O comportamento da fotossíntese é reflexo dos efetios verificados na condutância estomática (Tabela 1) e transpiração (Tabela 2), com reduções à medida que o déficit hídrico se acentuou, independentemente da quantidade de $\mathrm{K}$ fornecida, e aumento com a elevação na dose desse nutriente, além do efeito positivo da interação entre os tratamentos $50 \%$ cp x $100 \mathrm{mg} \mathrm{dm}^{3} \mathrm{~K}$.

Reduções na condutância estomática, taxa de transpiração e de fotossíntese devido o déficit hídrico têm sido relatadas em diversas espécies, a exemplo de Tabebuia aurea (OLIVEIRA, GUALTIERI e BOCCHESE, 2011), Khaya ivorensis A. Chev. (ALBUQUERQUE et al., 2013), Myracrodruon urundeuva (ALMEIDA et al., 2020), Handroanthus impetiginosus (DOMBROSKI et al., 2014; PESSOA, FREIRE e COSTA, 2017), Mimosa tenuiflora (ALVES; FREIRE, 2019; ALMEIDA et al., 2020) e Cnidoscolus phyllacanthus (RAMOS; FREIRE, 2019), sendo que a resposta variou com a espécie estudada, bem como com a intensidade do estresse hídrico imposto.

Diminuição na disponibilidade de água às plantas causa decréscimo no potencial hídrico foliar $\left(\Psi_{\mathrm{w}}\right)$, o qual resulta na perda da turgescência das células estomáticas e fechamento dos estômatos, um dos efeitos primários do déficit hídrico (FLEXAS et al., 2004), reduzindo a condutância estomática, a transpiração e a fotossíntese (FLEXAS et al., 2004; GOMES et al., 2004; PORTES et al., 2006; CHAVES, FLEXAS e PINHEIRO, 2009; ALBUQUERQUE et al., 2013). 
No entanto, os efeitos do déficit hídrico na fotossíntese não são apenas estomáticos, reduzindo reduzir a disponibilidade de $\mathrm{CO}_{2}$ à enzima rubisco, afetando a sua atividade (PINHEIRO; CHAVES, 2011), mas podem ser também devido a fatores não estomáticos. Dentre esses, podem ser citados a desestruturação das membranas dos tilacóides, afetando o sistema fotossintético (DIAS; BRÜGGERMANN, 2010) e decréscimo no transporte de elétrons no PSII e na síntese de ATP. Além disso, pode ocorrer redução na regeneração da RuBP (BOUSSADIA et al., 2008) e na atividade ou na capacidade e velocidade de regeneração da enzima Rubisco (FLEXAS et al., 2004).

Pelos resultados apresentados nas tabelas 1,2 e 3, verifica-se que o efeito prejudicial do déficit hídrico nas trocas gasosas das plantas de pereiro pode ser atenuado utilizando-se $100 \mathrm{mg} \mathrm{dm}^{3} \mathrm{~K}$ durante a produção das mudas, proporcionando melhoria no funcionamento dos estômatos.

$\mathrm{O}$ fornecimento do $\mathrm{K}$ pode ter proporcionado melhores condições hídricas às plantas, promovendo a abertura dos estômatos em virtude de reduzir o potencial osmótico das células-guarda, resultando na entrada de água para estas, aumentando a sua turgescência (TAIZ et al., 2017), favorecendo as trocas gasosas sob condições de menor disponibilidade hídrica. Diversos estudos relatam o papel central do potássio em proporcionar resistência aos efeitos adversos ocasionados pelos estresses abióticos (CAKMAK, 2005; MENDES et al., 2013; DIAS et al., 2019), em virtude do papel desempenhado pelo K em funções importantes as quais contribuem para a mitigação dos efeitos ocasionados pela seca. Esse íon é essencial na turgescência, manutenção de alto teor de água e osmorregulação das células (FOURNIER et al., 2005; MARENCO; LOPES, 2011; BATTIE-LACLAU et al., 2014), regulação estomática (ARQUERO et al., 2006; BENLLOCH-GONZÁLEZ et al., 2008; PASQUINI; SANTIAGO, 2011; ZAHOOR et al., 2017) e eliminação de espécies reativas de oxigênio (ROS), a qual garante a manutenção de área foliar fotossinteticamente ativa sob estresse hídrico (CHRISTINA et al., 2015).

Os efeitos positivos da adubação com K foram relatados por Mendes et al. (2013) que, avaliando as respostas fisiológicas de cinco genótipos de Eucalyptus grandis $x$ E. urophylla à disponibilidade hídrica e adubação potássica, verificaram que os genótipos sob deficiência hídrica e que receberam adubação com $\mathrm{K}$ apresentaram aumento no desempenho fisiológico com elevação em $A$ e E. Igualmente, Ramos e Freire (2019) em 
plantas de faveleira (Cnidoscolus quercifolius Pohl.) sob déficit hídrico constataram elevação em $A, E$ e $g s$ à medida que se aumentou as doses de $\mathrm{K}$.

\section{CONCLUSÕES}

A redução na disponibilidade de água do solo afetou as trocas gasosas das mudas de pereiro.

A adubação das mudas de pereiro com $100 \mathrm{mg} \mathrm{dm}{ }^{3} \mathrm{~K}$ e manutenção da umidade do substrato a $50 \%$ cp proporcionou maiores valores de condutância estomática, taxa fotossintética e eficiência de carboxilação.

\section{REFERÊNCIAS}

ALBUQUERQUE, M. P. F.; MORAES, F. K. C.; SANTOS, R. I. N.; CASTRO, G. L. S.; RAMOS, E. M. L. S.; PINHEIRO, H. A. Ecofisiologia de plantas jovens de mognoafricano submetidas a déficit hídrico e reidratação. Pesquisa Agropecuária Brasileira, Brasília, v. 48, n. 1, p. 9-16, 2013.

ALMEIDA, E. P. et al. Effects of potassium in Myracrodruon urundeuva, Libidibia ferrea and Mimosa tenuiflora seedlings under a short-term water deficit. Research, Society and Development, v. 9, n. 5, p. e97953269, 2020.

ALVES, F. J. B.; FREIRE, A. L. O. Gas exchange of Mimosa tenuiflora (Willd.) Poiret under water deficit and rewatering. Journal of Agricultural Studies, v. 7, n. 4, p. 297 308, 2019.

ARQUERO, O.; BARRANCO, D.; BENLLOCH, M. Potassium starvation increases stomatal conductance in olive trees. HortScience, v. 41, p. 433-436, 2006.

BATTIE-LACLAU, P. et al. Photosynthetic and anatomical responses of Eucalyptus grandis leaves to potassium and sodium supply in a field experiment. Plant, Cell \& Environment, v. 37, n. 1, p. 70-81, 2014.

BENLLOCH-GONZÁLEZ, M. et al. K+ starvation inhibits water-stress-induced stomatal closure. Journal of Plant Physiology, v. 165, p. 623-630, 2008.

BOUSSADIA, O. et al. Response to drought of two olive tree cultivars (cv Koroneki and Meski). Scientia Horticulturae, v. 116, p. 388-393, 2008.

BRAGA, R. Plantas do Nordeste - especialmente do Ceará. 3 ed. Mossoró: Fundação Vingt-un Rosado, 2015. 527p.

CAKMAK, I. The role of potassium in alleviating detrimental effects of abiotic stresses in plants. Journal of Plant Nutrition and Soil Science, v. 168, n. 4, p. 521-530, 2005.

CHAVES, M. M.; FLEXAS, J.; PINHEIRO, C. Photosynthesis under drought and salt stress: regulation mechanisms from whole plant to cell. Annals of Botany, v, 103, p. 551-560, 2009. 
CHAVES, M. M.; MAROCO, J. P.; PEREIRA, J. S. Understanding plant responses to drought - from genes to the whole plant. Functional Plant Biology, v. 30, n. 3, p. 239264, 2003.

CHRISTINA, M. et al. Measured and modeled interactive effects of potassium deficiency and water deficit on gross primary productivity and light-use efficiency in Eucalyptus grandis plantations. Global Change Biology, v. 21, n. 5, p. 2022-2039, 2015.

DIAS, A. S. et al. Gas exchanges, quantum yield and photosynthetic pigments of west indian cherry under salt stress and potassium fertilization. Revista Caatinga, v. 32, n. 2 , p. 429-439, 2019. DOI:

DIAS, M. C.; BRÜGGERMANN, W. Limitations of photosynthesis in Phaseolus vulgaris under drought stress: gas exchange, chlorophyll fluorescence and Calvin cicle enzyms. Photosynthetica, New York, v. 48, p. 96-102, 2010.

DOMBROSKI, J. L. D. et al. Ecophysiology of water stressed Handroanthus impetiginosus (Mart. Ex. DC) Mattos) seedlings. Scientia Forestalis, Piracicaba, v. 42, n. 101, p. 155-163, 2014.

FERNANDES-SILVA, A. A. et al. Leaf water relations and gas exchange response to water deficit of olive (cv. Cobrançosa) in field grown conditions in Portugal. Plant and Soil, v. 402, p. 191-209, 2016.

FLEXAS, J. et al. Diffusive and metabolic limitations to photosynthesis under drought and salinity in C3 plants. Plant Biology, v. 6, p. 269-279, 2004.

FOURNIER, J. M.; ROLDÁN, Á. M.; SÁNCHEZ, C.; ALEXANDRE, G.; BENLLOCH, M. K+ starvation increases water uptake in whole sunflower plants. Plant Science, v. 168, p. 823-829, 2005

FURTINI NETO, A. E. et al. Acidez do solo, crescimento e nutrição mineral de algumas espécies arbóreas, na fase de muda. Cerne, Lavras, v.5, n.2, p. 1-12, 1999.

GOMES, M. M. A. et al. Interactions between leaf water potential, stomatal conductance and abscisic acid content of orange trees submitted to drought stress.

Brazilian Journal of Plant Physiology, Londrina, v. 16, n. 3, p. 155-161, 2004.

IPCC. Climate Change 2014: Synthesis Report. Contribution of Working Groups I, II and III to the Fifth Assessment Report of the Intergovernmental Panel on Climate Change [Core Writing Team, R.K. Pachauri and L.A. Meyer (eds.)]. Geneva, Switzerland: IPCC, 2014. 151 p. ISBN 978-92-9169-143-2.

LARCHER, W. Ecofisiologia vegetal. São Carlos: RiMa Artes e Textos, 2004. 531 p.

LIMA, W. P.; JARVIS, P.; RHIZOPOULOU, S. Stomatal responses of Eucalyptus species to elevated $\mathrm{CO}_{2}$ concentration and drought stress. Scientia Agrícola, Piracicaba, v. 60, n. 2, p. 231-238, 2003.

MAIA, G. N. Caatinga - árvores e arbustos e suas utilidades. São Paulo D\&Z Computação Gráfica e Editora. p. 237-246, 2004.

MARENCO, R. A.; LOPES, N.F. Fisiologia vegetal: Fotossíntese, respiração, relações hídricas e nutrição mineral. 3ed. Editora UFV, Viçosa. 486p, 2011. 
MENDES, H. S. J. et al. Respostas fisiológicas de genótipos de Eucalyptus grandis x E. urophylla à disponibilidade hídrica e adubação potássica. Cerne, v.19, p.603- 611, 2013.

OLIVEIRA, A. K. M.; GUALTIERI, S. C. J.; BOCCHESE, R. A. Gas exchange of potted Tabebuia aurea plants under hydric stress. Acta Scientiarum. Agronomy, Maringá, v. 33, n. 4, p. 641-647, 2011

PADILHA, N. S. et al. Crescimento inicial do pinhão-manso submetido a diferentes regimes hídricos em latossolo vermelho distrófico. Ciência Florestal, Santa Maria, v. 26, n. 2, p. 513-521, 2016.

PASQUINI, S. C.; SANTIAGO, L. S. Nutrients limit photosynthesis in seedlings of a lowland tropical forest tree species. Oecologia, v. 168, p. 311-319, 2012.

PASSIOURA, J. The drought environment: physical, biological and agricultural perspectives. Journal of Experimental Botany, v. 58, p. 113-117, 2007.

PESSOA, J. L.; FREIRE, A. L. O.; COSTA, A. S. Trocas gasosas de plantas de Handroanthus impetiginosus (Mart. ex DC) Mattos submetidas ao déficit hídrico e posterior reidratação. Revista de Ciências Agroveterinárias, Lages, v. 16, n. 3, p. 269 276, 2017.

PINHEIRO, C.; CHAVES, M. M. Photosynthesis and drought: can we make metabolic connections from available data? Journal of Experimental Botany, v. 62, n. 3, p. 869$882,2011$.

PORTES, M. T.; ALVES, T. H.; SOUZA, G. M. Water deficit affects photosynthetic induction in Bauhinia forficata Link (Fabaceae) and Esenbeckia leiocarpa Engl. (Rutaceae) growing in understorey and gap conditions. Brazilian Journal of Plant Physiology, Campos dos Goytacazes, v. 18, n. 4, p. 491-502, 2006.

RAMOS, F. R.; FREIRE, A. L. O. Physiological responses of Cnidoscolus quercifolius Pohl in semi-arid conditions. Advances in Forestry Science, v.6, n.1, p.493-499, 2019.

SCALON, S. P. Q. et al. Estresse hídrico no metabolismo e crescimento inicial de mudas de mutambo (Guazuma ulmifolia Lam.). Ciência Florestal, Santa Maria, v. 21, n. 4, p. 655-662, 2011.

SILVA, F. A. S.; AZEVEDO, C. A. V. Assistente de Software Versão 7.7 e seu uso na análise de dados experimentais. African Journal of Agricultural Research, v. 11, n. 39, p. 3733-3740, 2016.

TAIZ, L.; ZEIGER, E. MØLLER, I. M.; MURPHY, A. Fisiologia e desenvolvimento vegetal. Porto Alegre: Artmed, 6. ed., 2017, 858 p.

VALADARES, J.; PAULA, N. F.; PAULA, R. C. Physiological changes in eucalyptus hybrids under different irrigation regimes. Revista Ciência Agronômica, Fortaleza, v. 45, n. 4, p. 805-814, 2014.

VANDOORNE, B. et al. Water stress drastically reduces root growth an inulin yield in Cichorium intybus (var. sativum) independently of photosynthesis. Journal of Experimental Botany, v. 63, n. 12, p. 4359-4373, 2012. 
ZAHOOR, R. et al. Potassium fertilizer improves drought stress alleviation potential in cotton by enhancing photosynthesis and carbohydrate metabolism. Environmental and Experimental Botany, v. 137, p. 73-83, 2017.

Recebido em: 20/01/2022

Aprovado em: 21/02/2022

Publicado em: 25/02/2022 